\title{
Lobular Carcinoma in Situ with Atypical Mass Presentation: a Case Report
}

\section{Carcinoma lobular in situ com apresentação nodular atípica: relato de caso}

\author{
Luciana Graziano $^{1}$ Almir Galvão Vieira Bitencourt ${ }^{1}$ Camila Souza Guatelli ${ }^{1}$ Juliana Alves Souza ${ }^{1}$ \\ Cynthia Aparecida Bueno de Toledo Osório ${ }^{2}$ Miriam Rosalina Brites Poli ${ }^{1}$ Elvira Ferreira Marques ${ }^{1}$ \\ ${ }^{1}$ Department of Imaging, AC Camargo Cancer Center, São Paulo, São \\ Paulo, Brazil \\ 2 Department of Pathology, AC Camargo Cancer Center, São Paulo, \\ Address for correspondence Luciana Graziano, MD, Department of \\ Imaging, AC Camargo Cancer Center, Rua Prof. Antônio Prudente, 211, \\ São Paulo - SP 01509-010, Brazil (e-mail: lugraziano79@gmail.com).
} São Paulo, Brazil

Rev Bras Ginec Obst 2016;38:112-116.

\begin{abstract}
Lobular carcinoma in situ (LCIS) is associated with an increased risk of breast cancer and accounts for 1 to $2 \%$ of all breast cancers. LCIS diagnosis currently remains one of the

Keywords

- breast

- cancer

- breast ultrasound

- mammography

\section{Resumo}

Palavras-chave

- mama

- carcinoma

- ultrassonografia mamária

- mamografia major identifiable risk factors for subsequent breast cancer development. Imaging methods are becoming increasingly sensitive, and the consequent detection of small lesions and subtle abnormalities increases the chance of detection of in situ and invasive carcinomas, leading to a reduction in mortality. This report describes a case of a palpable complaint with abnormal imaging findings, including a solid LCIS mass.

O Carcinoma Lobular in situ (CLIS) está associado a um aumento do risco de câncer de mama e representa $1-2 \%$ de todas as neoplasias mama. Atualmente, o diagnóstico de CLIS continua a ser um dos maiores fatores de risco identificáveis para o posterior desenvolvimento de câncer de mama. Os métodos de imagem estão cada vez mais sensíveis, fazendo com que a detecção de pequenas lesões e anormalidade sutis aumentem o risco de detecções de carcinomas in situ e invasivos, levando a diminuição da mortalidade. Neste relato será descrito um caso de queixa clínica palpável com alteração de achados de imagem como massa sólida de CLIS.
\end{abstract}

\section{Introduction}

Palpable lobular carcinoma in situ (LCIS) was first described in 1941 as a non-invasive lesion growing in the lobules and terminal ducts of the breast. ${ }^{1}$ The condition is defined by at least half of the acini in a lobe being filled and distended by monomorphic cells, and it is part of a spectrum of abnormalities called lobular intraepithelial neoplasia. ${ }^{2-4}$

received

July 8,2015

accepted

November 4, 2015

published online

February 3, 2016
DOI http://dx.doi.org/ 10.1055/s-0035-1571174 ISSN 0100-7203.
Lobular intraepithelial neoplasia is associated with an increased risk of breast cancer, ranging from 3 - to 4 -fold in the case of atypical lobular hyperplasia (ALH) to 8- to 10-fold in the case of LCIS. Diagnosis is usually more common among 40 - to 50 -year-old women, ${ }^{5} \sim 15$ years prior to the mean age at which an invasive carcinoma occurs ${ }^{2,3}$ and 7 to 8 years earlier than the occurrence of ductal carcinoma in situ (DCIS). ${ }^{6}$
Copyright $\odot 2016$ by Thieme Publicações License terms Ltda, Rio de Janeiro, Brazil
(ब) $\Theta \circledast$ 
LCIS is not associated with any clinical abnormality or imaging findings. ${ }^{4,7}$ It is usually found incidentally in biopsies and is associated with an increased risk of bilateral malignancy. ${ }^{3,8,9}$ It can be found in up to $3.6 \%$ of breast biopsies and is multicentric $\sim 68 \%$ of the time and bilateral in $\sim 30 \%$ of cases. ${ }^{3,8}$ However, the actual incidence is unknown because in most cases, it is not detectable by imaging methods. $^{4,10}$

The clinical picture is typically poor, and imaging tests do not seem to play a true role in LCIS diagnosis. Thus, the objective of this study is to report a case of LCIS that manifested as a palpable solid mass and changes in imaging.

\section{Case Report}

A female patient, 45 , was admitted to an oncological reference center presenting a palpable nodule in the right breast for 40 days. Previous routine exams had shown no changes. The patient reported no systemic diseases or cases of breast or ovarian cancer in the family.

Mammography showed dense breasts with slight architectural distortion in the projection of the upper quadrants in the palpable region (-Fig. 1). Ultrasonography showed a predominance of fibroglandular tissue with heterogeneous

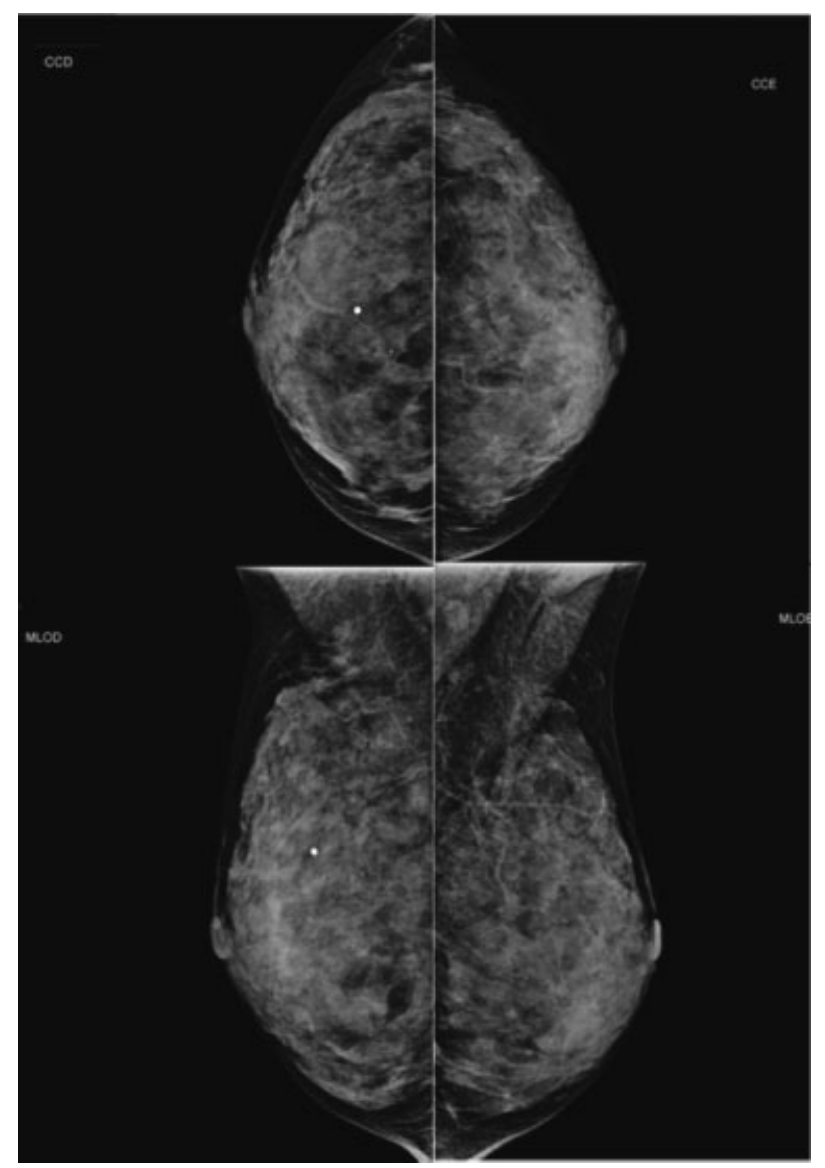

Fig. 1 Mammogram in craniocaudal (CC) and mediolateral oblique (MLO) views showing extremely dense breasts, with a metal marker at the junction of the upper quadrants of the right breast (palpation area reported by the patient). distribution and hypoechoic noduliform formation, irregular and poorly defined in the palpation region in the upper quadrants of the right breast (-Fig. 2).

We indicated histological analysis because of the imaging characteristics. The patient chose surgical resection after pre-operative localization by wire-guided ultrasound (-Fig. 3). Histological analysis revealed classical lobular carcinoma in situ, nuclear grade I, with positive margins, and without atypia or other significant associated histological lesions (-Fig. 4).

After discussing the case with the multidisciplinary team and following clinico-anatomical-radiologic correlation, the elected course of treatment was six-month follow-up and hormonal treatment with tamoxifen. After four years of follow-up, the patient remains asymptomatic, still uses tamoxifen, and remains without significant changes in imaging (-Fig. 5).

\section{Discussion}

Only rare cases of LCIS presenting as nodular lesions have been described in the literature. ${ }^{5,11,12}$ The case reported herein was unusual because, in addition to the clinical complaint of a palpable lesion, imaging tests showed changes

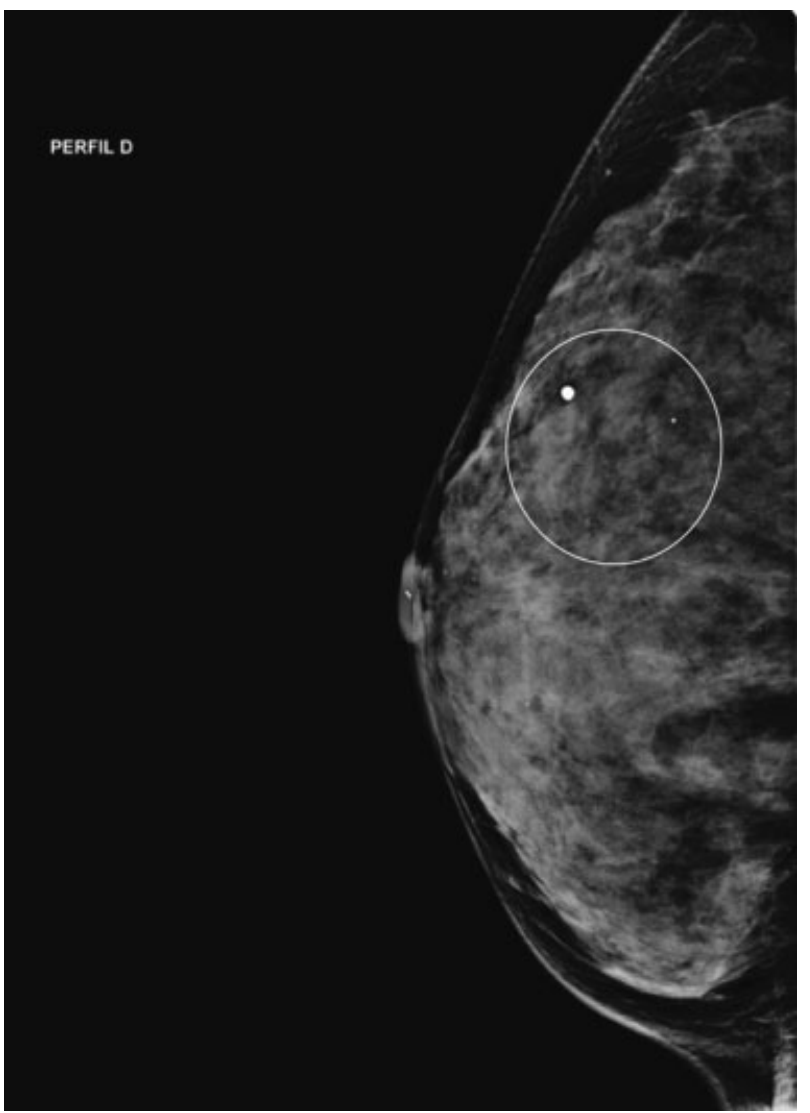

Fig. 2 Right mammography in absolute profile view showing an area of slight architectural distortion next to the metal marker at the junction of the upper quadrants of the right breast (palpation area reported by the patient). 


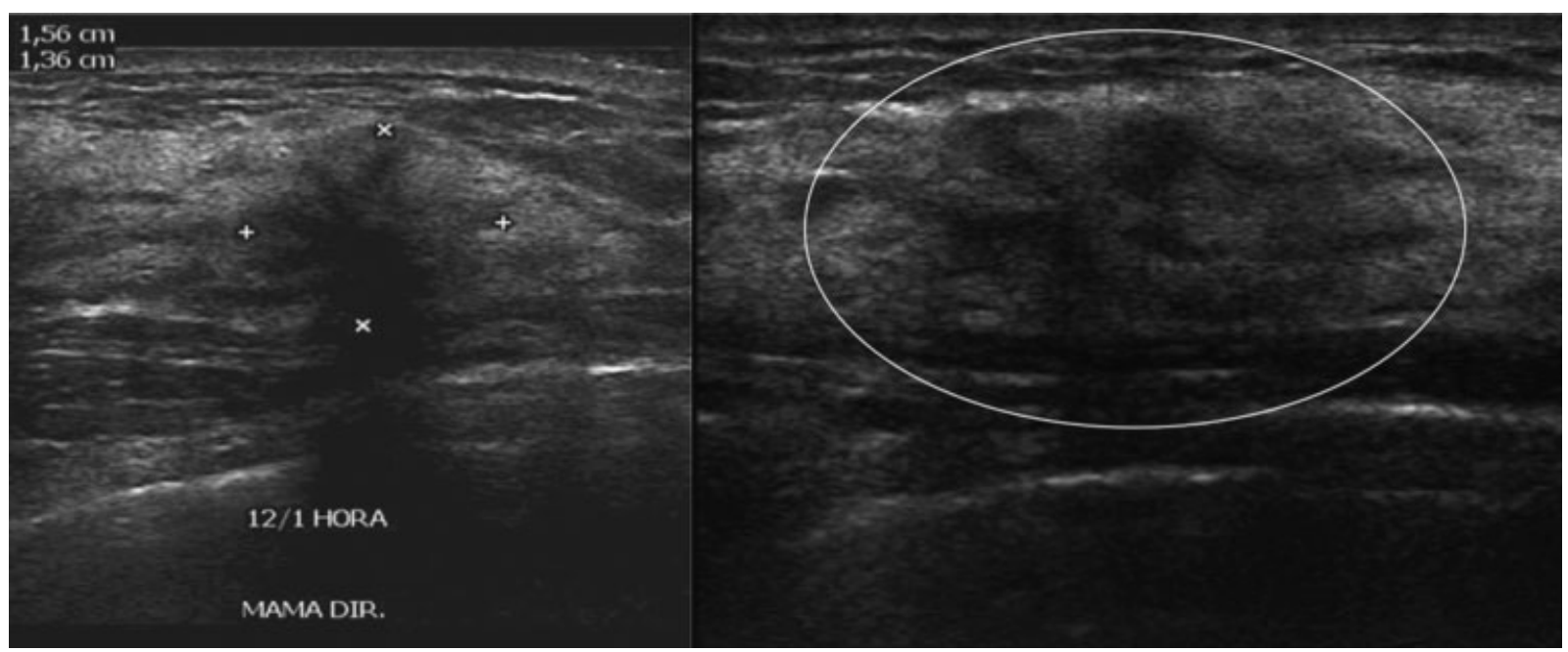

Fig. 3 Ultrasonography showing a hypoechoic noduliform formation, irregular and poorly defined, in the palpation region in the upper quadrants of the right breast.

that corresponded to this topography. Despite the positive surgical resection margins, we decided against performing margin extension. However, because of the increased risk of breast cancer development associated with LCIS, we indicated clinical and imaging monitoring every six months, combined with hormone therapy.

Initially, LCIS was considered a direct precursor to invasive lobular carcinoma and was treated with mastectomy, but a bilateral risk of invasive ductal or lobular disease was later demonstrated. ${ }^{13}$ Therefore, LCIS is considered a marker of increased risk rather than a true precursor. It usually occurs as an incidental finding, but studies have shown a correlation with imaging findings. 3,14

Imaging methods are becoming increasingly sensitive, and the consequent detection of small lesions and subtle abnormalities increases the chance of early detection of in

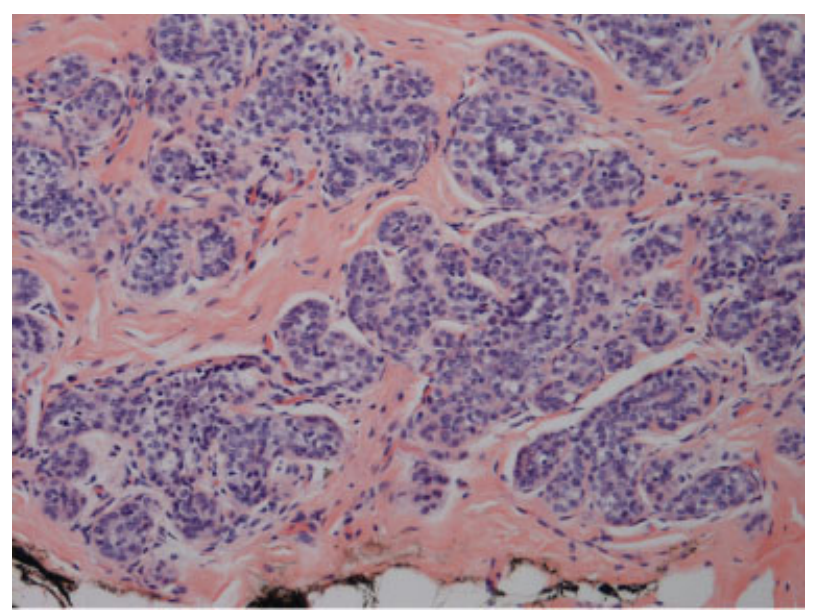

Fig. 4 Histology of the surgical specimen (hematoxylin-eosin, 50x) showing expansion and distortion of acini with monomorphic cell proliferation below the ductal epithelium, with no evidence of pleomorphism, necrosis, or atypia, consistent with classical lobular carcinoma in situ (LCIS). situ and invasive carcinomas. On imaging, LCIS can be found as calcifications in $\sim 21-67 \%$ of cases. ${ }^{11,14}$ The finding of a nodule on ultrasound, indeterminate enhancement on magnetic resonance imaging (MRI), or suspicious calcifications on mammography may be associated with the coexistence of other lesions. ${ }^{4}$ Although some studies have shown that the linear punctate microcalcifications found by mammography are related to the presence of LCIS, others have shown that this diagnosis associated with the presence of microcalcifications was an incidental finding. ${ }^{15,16}$ LCIS has been reported as a solid nodule of $20 \mathrm{~mm} .{ }^{5}$ In a published sample of four LCIS cases by core biopsy, there were two microcalcifications and two solid nodules, and only one was associated with DCIS on surgery, relating to a nodular lesion. ${ }^{17}$ In the mammography of the case reported herein, it was difficult to identify the lesion because of the high density of the breasts. The most evident finding was in the absolute profile view, conducted to better evaluate the palpable area. Ultrasound also did not reveal a classical finding, but because of the patient's clinical complaint, a more cautious evaluation was able to define the lesion.

Currently, LCIS diagnosis continues to be one of the largest identifiable risk factors for the later development of breast cancer. The risk of malignancy is 20 to $30 \%$ over the course of 15 to 20 years after initial LCIS diagnosis, and the most common form is ductal, with nearly half occurring in the contralateral breast. ${ }^{8,14}$ Over a period of 20 years, this type of pathology presents cumulative risks of cancer of $35 \%$ in the ipsilateral breast and $25 \%$ in the contralateral breast. ${ }^{18,19}$

There is currently no way to predict the occurrence of subsequent development of invasive carcinoma. However, it is believed that histological characteristics, including prognostic markers, genomic alterations, and factors relating to epithelial to mesenchymal transition and signaling pathways, are key to determining the progression to invasive disease. ${ }^{20}$ Histological differentiation between the LCIS patterns into classical, pleomorphic, associated with a mixed pattern with DCIS or LCIS with comedonecrosis can make a 


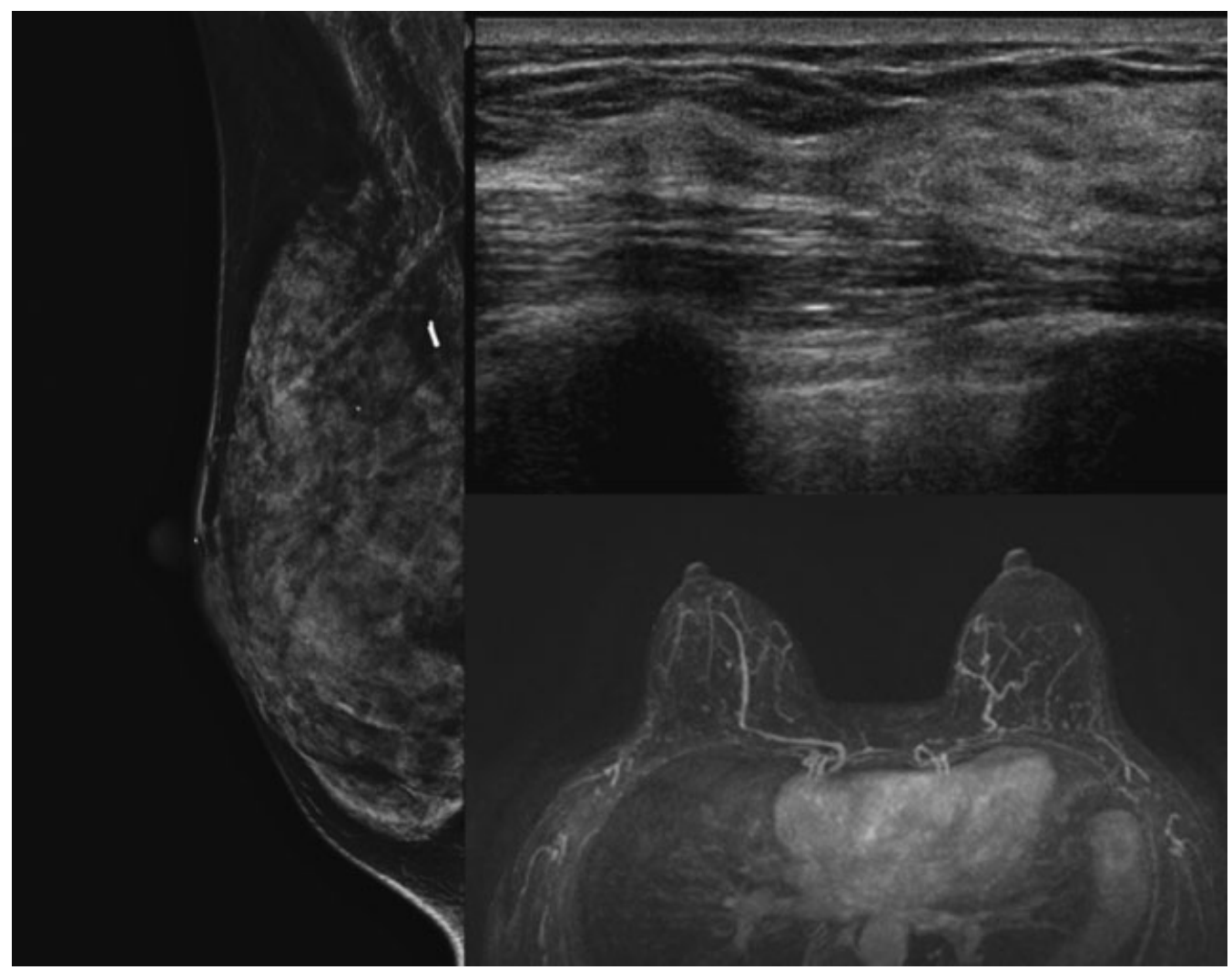

Fig. 5 Control imaging tests (mammography, ultrasound, and magnetic resonance imaging) four years after surgical treatment, demonstrating postoperative changes without evidence of suspicious lesions.

difference regarding treatment choice. Further investigation with surgical resection is indicated in all cases in which LCIS patterns, other than classical ones, are evidenced on percutaneous biopsy. ${ }^{4}$ Approximately 24 to $83 \%$ of surgeons reoperate in cases with margins compromised by pleomorphic LCIS because it seems that this type has a more worrying histological and immunohistochemical appearance than the classical form. ${ }^{21}$

Wide-core needle biopsy is the safest method for evaluating lesions detectable by imaging methods, with an accuracy of $98 \%$, although these lesions may be associated with other benign or malignant lesions. The literature shows an underestimation rate of LCIS ranging from 0 to $35 \%{ }^{4,22-24}$ However, it must be noted that these studies have some bias, and the number of evaluated cases, the lack of reviewed slides, the inclusion of cases of lobular neoplasia with other high-risk lesions, and the inclusion of high-risk LCIS variants, among other factors, should be considered. ${ }^{4}$ According to some studies, excisional biopsy is indicated in cases of high-risk lesions, including LCIS, ALH, and radial scar, because of the risk of underestimating the diagnosis in 1 to $46 \%$ of cases, as these entities may be associated with invasive lesions. ${ }^{1,2,25}$

The imaging-pathology correlation is essential for indicating whether follow-up is necessary. Furthermore, the risk of invasive disease increases when there is an association with other lesions, such as ductal hyperplasia, or first-degree family history of invasive cancer. ${ }^{6}$ Patients are offered one of three treatment options: lifetime monitoring to detect subsequent malignancy at an early stage; chemoprevention, with tamoxifen being the most used drug, as it reduces the risk of developing cancer in the subsequent four years by $56 \%$; or prophylactic bilateral mastectomy. ${ }^{26}$ Additionally, for patients with a positive classical LCIS margin, as in the present case, there is no consensus regarding reoperation, though $\sim 7 \%$ to $53 \%$ of surgeons choose to reoperate. ${ }^{21}$

In conclusion, LCIS is an important risk marker for the development of invasive breast cancer and is often an incidental finding of breast biopsies associated with other histological lesions. The anatomical-pathologic correlation is fundamental in these cases, and this evaluation should be performed in a multidisciplinary setting, considering both clinical and imaging findings. Although most LCISs do not present correspondence on imaging exams, we report a rare case of a palpable lesion visible on both ultrasound and mammography.

\section{References}

1 Middleton LP, Grant S, Stephens T, Stelling CB, Sneige N, Sahin AA. Lobular carcinoma in situ diagnosed by core needle biopsy: when should it be excised? Mod Pathol 2003;16(2):120-129

2 Foster MC, Helvie MA, Gregory NE, Rebner M, Nees AV, Paramagul C. Lobular carcinoma in situ or atypical lobular hyperplasia at core-needle biopsy: is excisional biopsy necessary? Radiology 2004;231(3):813-819 
3 Jorns J, Sabel MS, Pang JC. Lobular neoplasia: morphology and management. Arch Pathol Lab Med 2014;138(10):1344-1349

4 Chaudhary S, Lawrence L, McGinty G, Kostroff K, Bhuiya T. Classic lobular neoplasia on core biopsy: a clinical and radio-pathologic correlation study with follow-up excision biopsy. Mod Pathol 2013;26(6):762-771

5 Zhang X, Hanamura N, Yamasita M, Kashikura Y, Ogawa T, Taizo S. A case of lobular carcinoma in situ presenting as a solid mass. Br J Radiol 2011;84(999):e48-e50

6 Cutuli B, De Lafontan B, Kirova Y, et al. Lobular carcinoma in situ (LCIS) of the breast: is long-term outcome similar to ductal carcinoma in situ (DCIS)? Analysis of 200 cases. Radiat Oncol 2015;10(1):110

7 Beute BJ, Kalisher L, Hutter RV. Lobular carcinoma in situ of the breast: clinical, pathologic, and mammographic features. AJR Am J Roentgenol 1991;157(2):257-265

8 O'Neil M, Madan R, Tawfik OW, Thomas PA, Fan F. Lobular carcinoma in situ/atypical lobular hyperplasia on breast needle biopsies: does it warrant surgical excisional biopsy? A study of 27 cases. Ann Diagn Pathol 2010;14(4):251-255

9 Murray MP, Luedtke C, Liberman L, Nehhozina T, Akram M, Brogi E. Classic lobular carcinoma in situ and atypical lobular hyperplasia at percutaneous breast core biopsy: outcomes of prospective excision. Cancer 2013;119(5):1073-1079

10 Nagi CS, O’Donnell JE, Tismenetsky M, Bleiweiss IJ, Jaffer SM. Lobular neoplasia on core needle biopsy does not require excision. Cancer 2008;112(10):2152-2158

11 Stein LF, Zisman G, Rapelyea JA, Schwartz AM, Abell B, Brem RF. Lobular carcinoma in situ of the breast presenting as a mass. AJR Am J Roentgenol 2005;184(6):1799-1801

12 Christiano JG, Duncan LD, Bell JL. Lobular carcinoma in situ of the breast presenting as a discrete mass. Am Surg 2012;78(1):E38-E40

13 Lakhani SR, Audretsch W, Cleton-Jensen AM, et al; EUSOMA. The management of lobular carcinoma in situ (LCIS). Is LCIS the same as ductal carcinoma in situ (DCIS)? Eur J Cancer 2006;42(14): 2205-2211

14 O'Driscoll D, Britton P, Bobrow L, Wishart GC, Sinnatamby R, Warren R. Lobular carcinoma in situ on core biopsy-what is the clinical significance? Clin Radiol 2001;56(3):216-220
15 Snyder RE. Mammography and lobular carcinoma in situ. Surg Gynecol Obstet 1966;122(2):255-260

16 Hutter RV, Snyder RE, Lucas JC, Foote FW Jr, Farrow JH. Clinical and pathologic correlation with mammographic findings in lobular carcinoma in situ. Cancer 1969;23(4):826-839

17 Philpotts LE, Shaheen NA, Jain KS, Carter D, Lee CH. Uncommon high-risk lesions of the breast diagnosed at stereotactic coreneedle biopsy: clinical importance. Radiology 2000;216(3): 831-837

18 Foote FW, Stewart FW. Lobular carcinoma in situ: A rare form of mammary cancer. Am J Pathol 1941;17(4):491-496, 3

19 McDivitt RW, Hutter RV, Foote FW Jr, Stewart FW. In situ lobular carcinoma. A prospective follow-up study indicating cumulative patient risks. JAMA 1967;201(2):82-86

20 Logan GJ, Dabbs DJ, Lucas PC, et al. Molecular drivers of lobular carcinoma in situ. Breast Cancer Res 2015;17:76

21 Blair SL, Emerson DK, Kulkarni S, Hwang ES, Malcarne V, Ollila DW. Breast surgeon's survey: no consensus for surgical treatment of pleomorphic lobular carcinoma in situ. Breast J 2013;19(1): 116-118

22 Elsheikh TM, Silverman JF. Follow-up surgical excision is indicated when breast core needle biopsies show atypical lobular hyperplasia or lobular carcinoma in situ: a correlative study of 33 patients with review of the literature. Am J Surg Pathol 2005; 29(4):534-543

23 Arpino G, Allred DC, Mohsin SK, Weiss HL, Conrow D, Elledge RM. Lobular neoplasia on core-needle biopsy-clinical significance. Cancer 2004;101(2):242-250

24 Zhao C, Desouki MM, Florea A, Mohammed K, Li X, Dabbs D. Pathologic findings of follow-up surgical excision for lobular neoplasia on breast core biopsy performed for calcification. Am J Clin Pathol 2012;138(1):72-78

25 Destounis SV, Murphy PF, Seifert PJ, et al. Management of patients diagnosed with lobular carcinoma in situ at needle core biopsy at a community-based outpatient facility. AJR Am J Roentgenol 2012;198(2):281-287

26 Oppong BA, King TA. Recommendations for women with lobular carcinoma in situ (LCIS). Oncology (Williston Park) 2011;25(11): 1051-1056, 1058 